University of Nebraska - Lincoln

DigitalCommons@University of Nebraska - Lincoln

5-15-2005

\title{
The effects of the thickness of magnetically hard- and soft-phase layers on magnetic properties and exchange coupling in multilayer magnets
}

W. Liu

University of Nebraska - Lincoln

Yucheng Sui

University of Nebraska-Lincoln, ysui2@unl.edu

J. Zhou

University of Nebraska - Lincoln

\section{X.K. Sun}

Shenyang National Laboratory for Materials Science, Institute of Metal Research and International Center for Materials Physics, Chinese Academy of Sciences, Shenyang, People's Republic of China

\section{C.L. Chen}

Shenyang National Laboratory for Materials Science, Institute of Metal Research and International Center for Materials Physics, Chinese Academy of Sciences, Shenyang, People's Republic of China

See next page for additional authors

Follow this and additional works at: https://digitalcommons.unl.edu/physicssellmyer

Part of the Physics Commons

Liu, W.; Sui, Yucheng; Zhou, J.; Sun, X.K.; Chen, C.L.; Zhang, Z.D.; and Sellmyer, David J., "The effects of the thickness of magnetically hard- and soft-phase layers on magnetic properties and exchange coupling in multilayer magnets" (2005). David Sellmyer Publications. 15.

https://digitalcommons.unl.edu/physicssellmyer/15

This Article is brought to you for free and open access by the Research Papers in Physics and Astronomy at DigitalCommons@University of Nebraska - Lincoln. It has been accepted for inclusion in David Sellmyer Publications by an authorized administrator of DigitalCommons@University of Nebraska - Lincoln. 


\section{Authors}

W. Liu, Yucheng Sui, J. Zhou, X.K. Sun, C.L. Chen, Z.D. Zhang, and David J. Sellmyer 


\title{
The effects of the thickness of magnetically hard- and soft-phase layers on magnetic properties and exchange coupling in multilayer magnets
}

\author{
W. Liu ${ }^{\text {a) }}$ \\ Shenyang National Laboratory for Materials Science, Institute of Metal Research and International Centre \\ for Materials Physics, Chinese Academy of Sciences, Shenyang 110016, People's Republic of China \\ and Center for Materials Research and Analysis, University of Nebraska, \\ Lincoln, Nebraska 68588-0113 \\ Y. C. Sui and J. Zhou \\ Center for Materials Research and Analysis, University of Nebraska, Lincoln, Nebraska 68588-0113
}

X. K. Sun, C. L. Chen, and Z. D. Zhang

Shenyang National Laboratory for Materials Science, Institute of Metal Research and International Center for Materials Physics, Chinese Academy of Sciences, Shenyang 110016, People's Republic of China

D. J. Sellmyer

Center for Materials Research and Analysis, University of Nebraska, Lincoln, Nebraska 68588-0113

(Presented on 11 November 2004; published online 13 May 2005)

\begin{abstract}
The structure and magnetic properties of multilayer magnets containing a hard phase [HP $\left.\equiv\left(\mathrm{Nd}_{0.95} \mathrm{Dy}_{0.05}\right)(\mathrm{Fe}, \mathrm{Co}, \mathrm{Nb}, \mathrm{B})_{5.5}\right]$ and a soft phase $\left(\mathrm{SP} \equiv \mathrm{Fe}\right.$ and $\left.\mathrm{Fe}_{65} \mathrm{Co}_{35}\right)$ have been investigated. For the nanocomposite multilayer of $\operatorname{Si}($ substrate $) / \operatorname{Ti}(30 \mathrm{~nm}) /[\mathrm{HP}(x \mathrm{~nm}) / \mathrm{SP}(y \mathrm{~nm})] n /$ $\operatorname{Ti}(30 \mathrm{~nm})$, the remanence enhancement has been observed at different thickness and volume fractions of hard- and soft-phase layers. The remanence increases and the coercivity decreases with the addition of soft phase, in comparison with the results of the single-layer film. For the multilayer of $\mathrm{Si}($ substrate $) / \operatorname{Ti}(30 \mathrm{~nm}) /[\mathrm{HP}(15 \mathrm{~nm}) / \mathrm{Fe}(5 \mathrm{~nm})] \mathrm{n} / \mathrm{Ti}(30 \mathrm{~nm})$ annealed at $575{ }^{\circ} \mathrm{C}$ for $30 \mathrm{~min}$, the coercivity of the multilayer reaches a maximum at $n=20$. Effects of the layer thickness and volume fraction of hard- and soft-phase layers on magnetic properties and exchange coupling in the multilayer films have been observed. (C) 2005 American Institute of Physics.
\end{abstract}

[DOI: $10.1063 / 1.1847371]$

\section{INTRODUCTION}

Experimental researches on nanostructured exchangecoupled magnets have been performed since $1988 .{ }^{1}$ Taking advantage of a high coercivity and a high magnetization provided by the hard- and the soft-magnetic components, respectively, a high remanence and a large maximum energy product would be obtained if a full and perfect exchange coupling existed between the grains of the two phases in nanocomposite magnets, as predicted by micromagnetic calculations. $^{2-4}$ However, up to now, the energy products of the rare-earth nanocomposite magnets prepared by means of rapid quenching and mechanical alloying have been much lower than the theoretical expectation, due to difficulties in controlling the nanostructures. ${ }^{5-8}$ Recently, some studies on exchange coupling were carried out for nanostructured $\mathrm{CoSm} / \mathrm{FeCo}$ and $\mathrm{PrCo} / \mathrm{Co}$ multilayers prepared by sputtering and subsequent heat treatment. ${ }^{9,10}$ The magnetic properties of exchange-coupled $\alpha$ - $\mathrm{Fe} / \mathrm{Nd}-\mathrm{Fe}-\mathrm{B}$ multilayer magnets were investigated by Shindo and Ishizone ${ }^{11}$ and the observations for $\mathrm{Nd}-\mathrm{Fe}-\mathrm{B} / \mathrm{Fe} / \mathrm{Nd}-\mathrm{Fe}-\mathrm{B}$ trilayers were reported by Parhofer et al. ${ }^{12,13}$ and Yang and Kim. ${ }^{14}$ In our previous

\footnotetext{
a) Author to whom correspondence should be addressed; present address: Institute of Metals Research, Chinese Academy of Sciences, Shenyang, 110016, P.R. China; FAX: 86-24-23891320; electronic mail:wliu@imr.ac.cn
}

study, ${ }^{15}$ a high remanence of $J_{r}=1.31 \mathrm{~T}$ and a relatively large maximum energy product of $(B H)_{\max }=203 \mathrm{~kJ} / \mathrm{m}^{3}(25.5$ MG Oe) were achieved in the nanocomposite ( $\mathrm{Nd}, \mathrm{Dy})$ $\times(\mathrm{Fe}, \mathrm{Co}, \mathrm{Nb}, \mathrm{B})_{5.5} / \alpha$-Fe multilayer films on glass ceramic substrates. Well-designed multilayer films consist of a magnetically hard $\mathrm{Nd}_{2} \mathrm{Fe}_{14} \mathrm{~B}$-type phase with an average grain size of $40 \mathrm{~nm}$ and a magnetically soft $\alpha$-Fe phase existing in the form of continuous layers. ${ }^{15}$ In the present work, the content of Dy of the alloy target is reduced, and the effects of the thickness of magnetically hard- and soft-phase layers on magnetic properties and exchange coupling in multilayer magnets are investigated.

\section{EXPERIMENT}

$(\mathrm{Nd}, \mathrm{Dy})(\mathrm{Fe}, \mathrm{Co}, \mathrm{Nb}, \mathrm{B})_{5.5} / \alpha$-Fe thin films were prepared with a multiple-gun dc- and rf-sputtering system by depositing $\left(\mathrm{Nd}_{0.95} \mathrm{Dy}_{0.05}\right)\left(\mathrm{Fe}_{0.77} \mathrm{Co}_{0.12} \mathrm{Nb}_{0.03} \mathrm{~B}_{0.08}\right)_{5.5}$ alloy and $\mathrm{Fe}$ onto silicon or glass ceramic substrates, covered with a Ti buffer of $30 \mathrm{~nm}$. The alloy target was made by sintering powdered compacts, while other targets were commercial products. Purities of all the targets were higher than $99.9 \%$. The base pressure of the sputtering system was (2-3) $\times 10^{-7}$ Torr and the Ar pressure during the sputtering was 5 mTorr. The thickness of the films was measured by weighing samples. The substrate temperature is at room temperature 
$\mathrm{Si} / \mathrm{Ti}(30 \mathrm{~nm}) /[\mathrm{HP}(15 \mathrm{~nm}) / \mathrm{Fe}(\mathrm{ynm})]^{*} 20 / \mathrm{Ti}(30 \mathrm{~nm})$

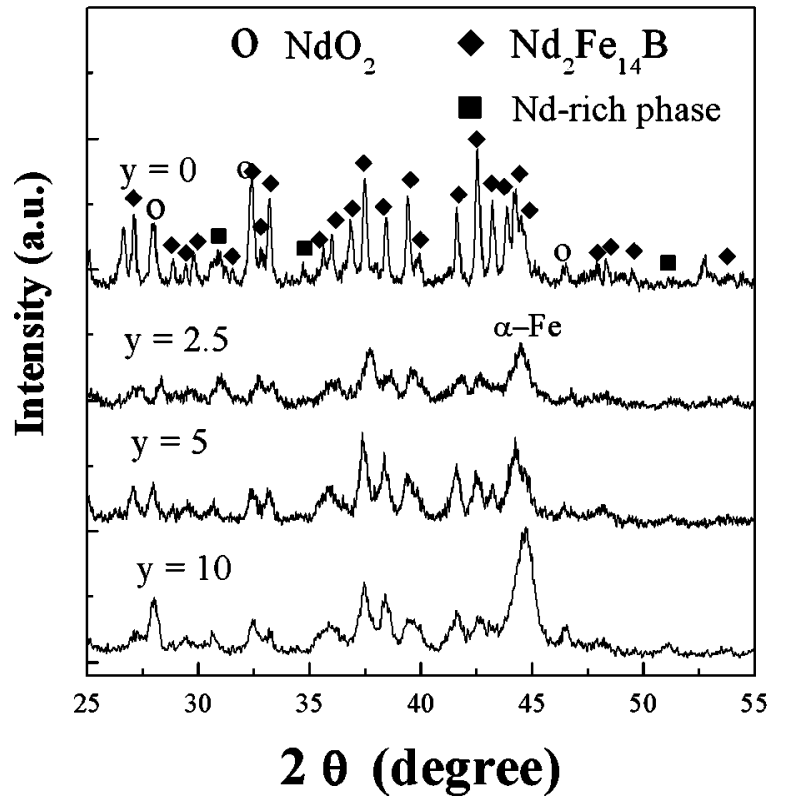

FIG. 1. XRD patterns for (Si substrate) $/ \mathrm{Ti}(30 \mathrm{~nm}) /[\mathrm{HP}(15 \mathrm{~nm}) \mathrm{Fe}(y$ $\mathrm{nm})] 20 / \mathrm{Ti}(30 \mathrm{~nm})$ multilayers annealed at $600{ }^{\circ} \mathrm{C}$ for $5 \mathrm{~min}$.

with an attached cooling water system during sputtering. The as-deposited films were annealed in a furnace with a vacuum of $2 \times 10^{-7}$ Torr. The crystalline structure of the phases in the films was identified by $\mathrm{x}$-ray diffractometry with $\mathrm{Cu} K \alpha$ radiation and by transmission electron microscopy (TEM). The magnetic properties of the films were measured by an alternating-gradient force magnetometer (AGFM) and a superconducting quantum interference device (SQUID) magnetometer. The measuring field was applied in the plane of the film and the demagnetization coefficient was effectively zero.

\section{RESULTS AND DISCUSSION}

X-ray diffraction (XRD) patterns for (Si substrate)/ $\mathrm{Ti}(30 \mathrm{~nm}) /[\mathrm{HP}(15 \mathrm{~nm}) \mathrm{Fe}(y \mathrm{~nm})] 20 / \mathrm{Ti}(30 \mathrm{~nm})$ multilayers annealed at $600{ }^{\circ} \mathrm{C}$ for $5 \mathrm{~min}$ are given in Fig. 1. The asdeposited HP single-layer films for $y=0$ are amorphous. After annealing, the main phase is of the $\mathrm{Nd}_{2} \mathrm{Fe}_{14} \mathrm{~B}$ type, accompanied by a little Nd-rich phase and a trace of $\mathrm{NdO}_{2}$. When the soft-phase Fe is added to the hard phase, the asdeposited multilayer films including soft- and hard-phase layers are homogeneous, as shown in our previous work. ${ }^{15}$ It can be seen from Fig. 1 that the hard-magnetic phase of $\mathrm{Nd}_{2} \mathrm{Fe}_{14} \mathrm{~B}$ type coexists with a large amount of $\alpha$-Fe, accompanied by a trace of $\mathrm{NdO}_{2}$ after annealing. With an increase of the thickness of the Fe layer, the quantity of $\alpha$-Fe increases in multilayer films. The XRD profiles of the films reveal a random orientation of the grains of the $\mathrm{Nd}_{2} \mathrm{Fe}_{14} \mathrm{~B}$-type phase.

Figure 2 gives hysteresis loops at room temperature of the thin films of (Si substrate) $/ \mathrm{Ti}(30 \mathrm{~nm}) /[\mathrm{HP}(15$ $\mathrm{nm}) \mathrm{Fe}(y \mathrm{~nm})] 20 / \mathrm{Ti}(30 \mathrm{~nm})$ multilayer films annealed at $600{ }^{\circ} \mathrm{C}$ for $5 \mathrm{~min}$. It can be seen from Fig. 2 that the intrinsic coercivity of the single layer for $y=0$ is as high as $16.6 \mathrm{kOe}$,

\section{$\mathrm{Si} / \mathrm{Ti}(30 \mathrm{~nm}) /[\mathrm{HP}(15 \mathrm{~nm}) \mathrm{Fe}(\mathrm{ynm})]^{* 20 / \mathrm{Ti}(30 \mathrm{~nm})}$}

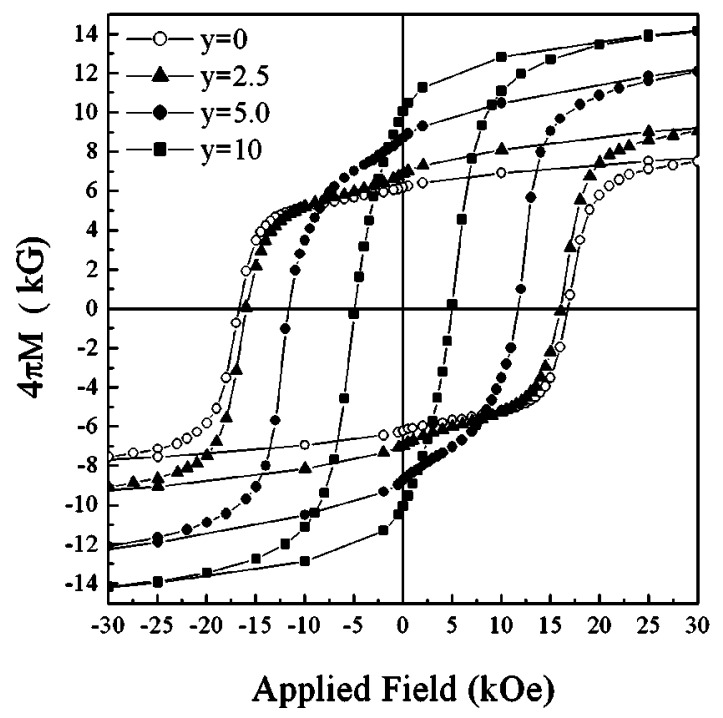

FIG. 2. Hysteresis loops at room temperature of the multilayer films of $($ Si substrate $) / \operatorname{Ti}(30 \mathrm{~nm}) /[\mathrm{HP}(15 \mathrm{~nm}) \mathrm{Fe}(y \mathrm{~nm})] 20 / \mathrm{Ti}(30 \mathrm{~nm})$ annealed at $600{ }^{\circ} \mathrm{C}$ for $5 \mathrm{~min}$.

but the remanence is only $6.2 \mathrm{kG}$ and its maximum magnetic energy product is $8.6 \mathrm{MG}$ Oe. For $y=2.5$, the coercivity decreases and the remanence increases slightly. When the thickness of $\mathrm{Fe}$ is up to $5.0 \mathrm{~nm}$, although the coercivity is reduced to $11.6 \mathrm{kOe}$, the remanence is enhanced clearly, and the maximum magnetic energy product is enhanced to 14 MG Oe. Compared with the results for the single layer, the remanence enhancement and the large maximum magnetic energy product in the nanocomposite multilayer are attributed to the exchange coupling between the nanograins of the soft and hard phases. If the exchange coupling were perfect, i.e., essentially all hard and soft grains were effectively coupled, after the soft phase Fe is added, the magnetic properties would be improved. In fact, when the thickness of Fe

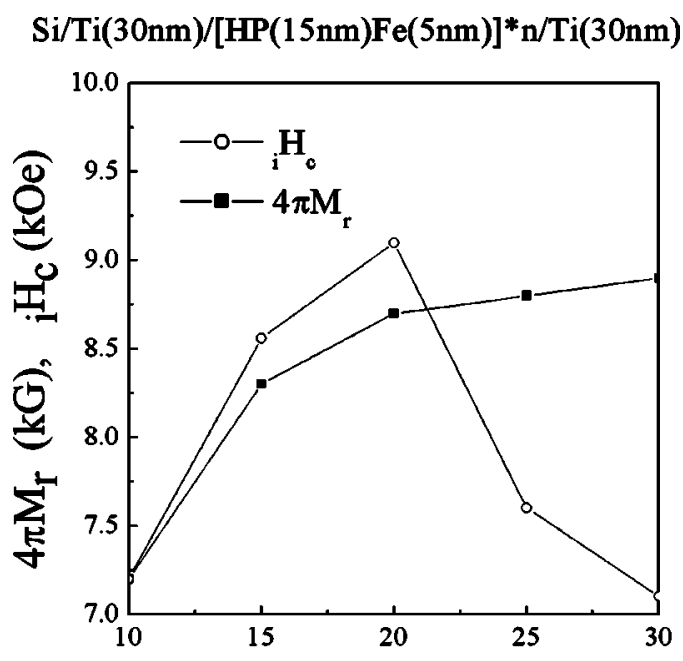

Period number $\mathbf{n}$

FIG. 3. Dependence of the remanence and coercivity on period number $n$ of $\mathrm{Si}$ (substrate) $/ \mathrm{Ti}(30 \mathrm{~nm}) /[\mathrm{HP}(15 \mathrm{~nm}) \mathrm{Fe}(5 \mathrm{~nm})] n / \mathrm{Ti}(30 \mathrm{~nm}) \quad$ multilayer films annealed at $575{ }^{\circ} \mathrm{C}$ for $30 \mathrm{~min}$. 
TABLE I. Reduced remanence $M_{r} / M_{s}$ and magnetic properties of the $\mathrm{Si}$ (substrate)/ $\mathrm{Ti}(30 \mathrm{~nm}) /[\mathrm{HP}(x \mathrm{~nm}) \mathrm{FeCo}(y \mathrm{~nm})] 20 / \mathrm{Ti}(30 \mathrm{~nm})$ multilayer films annealed at $625^{\circ} \mathrm{C}$ for $1 \mathrm{~min}$ with different designed layer thickness and volume fractional ratio $f_{h}: f_{s}$ of the hard and soft phases.

\begin{tabular}{clccccc}
\hline \hline No. & Designed layer thickness & $f_{h}: f_{s}$ & $M_{r} / M_{s}$ & $\begin{array}{c}4 \pi M_{r} \\
(\mathrm{kG})\end{array}$ & $\begin{array}{c}{ }_{i} H_{c} \\
(\mathrm{kOe})\end{array}$ & $\begin{array}{c}(B H)_{\max } \\
(\mathrm{MG} \mathrm{Oe})\end{array}$ \\
\hline 1 & $\mathrm{HP}(20 \mathrm{~nm}) / \mathrm{FeCo}(7.5 \mathrm{~nm})$ & $0.73: 0.27$ & 0.67 & 9.0 & 7.3 & 13.4 \\
2 & $\mathrm{HP}(15 \mathrm{~nm}) \mathrm{FeCo}(7.5 \mathrm{~nm})$ & $0.67: 0.33$ & 0.66 & 9.1 & 7.0 & 11.3 \\
3 & $\mathrm{HP}(20 \mathrm{~nm}) \mathrm{FeCo}(10 \mathrm{~nm})$ & $0.67: 0.33$ & 0.66 & 10.1 & 6.5 & 12.7 \\
\hline \hline
\end{tabular}

increases to $10 \mathrm{~nm}$, the remanence increases to $10 \mathrm{kG}$, but the coercivity is decreased to $4.9 \mathrm{kOe}$; thus, a high maximum magnetic energy product is impossible. Although the addition of soft-phase Fe results in the reduction of the effective anisotropy field of the multilayer film, the main reason for poor magnetic properties may be that after annealing the two phases in the two layers diffuse into each other, as shown in our previous work. ${ }^{16}$ However, for such a structure, the enhancement of the remanence, to some extent, is still possible.

The dependence of the remanence and coercivity on the period number $n$ of the $\mathrm{Si}$ (substrate)/Ti(30 nm)/[HP(15 $\mathrm{nm}) \mathrm{Fe}(5 \mathrm{~nm})] n / \mathrm{Ti}(30 \mathrm{~nm})$ multilayer films annealed at $575^{\circ} \mathrm{C}$ for $30 \mathrm{~min}$ is shown in Fig. 3. With an increase of $n$, the remanence of the multilayer films increases quickly at the beginning and then slightly for $n \geqslant 20$. After annealing, the cover layer and underlayer diffuse into the magnetic multilayer close to them, which will reduce the remanence of the multilayer films. It is evident that the smaller $n$ is, the smaller the remanence. On the other hand, when $n$ increases, the coercivity of the multilayer films increases at first, reaches a maximum at $n=20$, and then decreases. Here, a clear effect of the period number has been observed. In fact, the thickness of the multilayer films may critically influence the nanostructure of the multilayer magnets. ${ }^{16}$ To understand the physical origin of this phenomenon in detail, further work including high-resolution TEM is needed.

The reduced remanence $M_{r} / M_{s}$ and the magnetic properties of the $\mathrm{Si}$ (substrate)/Ti(30 nm) $/[\mathrm{HP}(x \mathrm{~nm}) \mathrm{FeCo}(y$ $\mathrm{nm})] 20 / \mathrm{Ti}(30 \mathrm{~nm})$ multilayer films annealed at $625^{\circ} \mathrm{C}$ for 1 min, with different film thickness and volume fractional ratio $f_{h}: f_{s}$ of hard and soft phases are shown in Table I. Compared with samples 1 and 2, for the same thickness of soft-phase layer, the thickness of the hard-phase layer of the former is larger than that of the latter. The coercivity and maximum magnetic energy product of the former are higher than the latter. Although the volume fractional ratio of the hard and soft phases of samples 3 and 2 are the same, since the thickness of both hard- and soft-phase layers of sample 3 is larger than that of sample 2 , the remanence and the maximum magnetic energy product of the former are slightly higher than those of the latter. According to the TEM results in our previous work, ${ }^{16}$ when the thickness of the soft-phase layer is more than $7.5 \mathrm{~nm}$, the soft-phase layer will not be completely broken and the grains of the hard- and soft-phase layers will fail to diffuse completely into each other. Although a large remanence enhancement has been observed, the limited exchange coupling between the soft and the hard phases could not lead to a high maximum magnetic energy product due to low coercivity.

In summary, we prepared nanocomposite multilayer magnets containing a $\mathrm{Nd}_{2} \mathrm{Fe}_{14} \mathrm{~B}$-type hard phase and soft phase $\left(\mathrm{Fe}\right.$ and $\mathrm{Fe}_{65} \mathrm{Co}_{35}$ ) by sputtering and subsequent heat treatment. In hard-phase single-layer films, the reduction of the anisotropy field of the hard phase by reduction of the Dy content did not lead to a reduction of the coercivity. A noticeable effect of the period number on coercivity has been observed. The exchange coupling is dependent on the designed layer thickness and volume fractional ratio of the hard and soft phases, critically influencing the magnetic properties. The enhancement of the magnetic properties in the nanocomposite multilayer films can be well explained by means of the exchange coupling between the soft and hard magnetic nanograins of the intra- and interlayers.

\section{ACKNOWLEDGMENT}

This work has been supported by NSF-MRSEC, DOE, ARO, AFOSR, CMRA, the National Natural Science Foundation of China under Project Nos. 50331030 and 50371085, and the National 863 project under Grant No. 2002AA302603.

${ }^{1}$ R. Coehoorn, D. B. de Mooji, and C. D. E. Waard, J. Magn. Magn. Mater. 80, 101 (1989).

${ }^{2}$ R. Skomski and J. M. D. Coey, Phys. Rev. B 48, 15812 (1993).

${ }^{3}$ T. Schrefl, H. Kromüller, and J. Fidler, J. Magn. Magn. Mater. 127, L237 (1993).

${ }^{4}$ E. F. Kneller and R. Hawig, IEEE Trans. Magn. 27, 3588 (1991).

${ }^{5}$ J. Ding, P. G. McCormick, and R. Street, J. Magn. Magn. Mater. 124, 1 (1993).

${ }^{6}$ A. Manaf, R. A. Buckley, and H. A. Davies, J. Magn. Magn. Mater. 128, 302 (1993).

${ }^{7}$ L. Withanawasam, A. S. Hurphy, G. C. Hadjipanayis, and R. F. Krause, J. Appl. Phys. 75, 7065 (1994).

${ }^{8}$ X. K. Sun, J. Zhang, Y. L. Chu, W. Liu, B. Z. Cui, and Z. D. Zhang, Appl. Phys. Lett. 74, 1740 (1999).

${ }^{9}$ I. A. Al-Omari and D. J. Sellmyer, Phys. Rev. B 52, 3441 (1995).

${ }^{10}$ J. P. Liu, Y. Liu, R. Skomski, and D. J. Sellmyer, IEEE Trans. Magn. 35, 3241 (1999).

${ }^{11}$ M. Shindo and M. Ishizone, J. Appl. Phys. 81, 4444 (1997).

${ }^{12}$ S. Parhofer, J. Wecker, C. Kuhrt, and G. Gieres, IEEE Trans. Magn. 32, 4437 (1996).

${ }^{13}$ S. Parhofer, G. Gieres, J. Wecker, and L. Schultz, J. Magn. Magn. Mater. 163, 32 (1996).

${ }^{14}$ C. J. Yang and S. W. Kim, J. Magn. Magn. Mater. 202, 311 (1999).

${ }^{15}$ W. Liu, Z. D. Zhang, J. P. Liu, L. J. Chen, L. L. He, Y. Liu, X. K. Sun, and D. J. Sellmyer, Adv. Mater. (Weinheim, Ger.) 14, 1832 (2002).

${ }^{16}$ W. Liu, Z. D. Zhang, J. P. Liu, Z. R. Dai, Z. L. Wang, X. K. Sun, and D. J. Sellmyer, J. Phys. D 36, L63 (2003). 